major US chemical companies, says that while such tests have value as screening tools, they are too unreliable as predictors of human responses to be sufficient to warrant regulatory action.

The council recommends that emphasis should be placed both on data from animals exposed to low levels of potential carcinogens over normal lifespans, and where prior worker exposure has occurred, on human epidemiological data. It rejects the notion that it is realistic to impose a "no risk" approach to potential carcinogens, and suggests rather the development of dose-risk data, using risk/benefit analysis to determine acceptable-risk levels of exposure.

The council also suggests that the National Academy of Sciences should set up a classification panel to examine the hazards of potential and known carcinogens, which would be responsible both for proper category assignments and for the modification of categories as relevant advances in science dictate.

AIHC believes that setting up such a panel would provide some degree of insulation from a wide variety of

"political and other pressures" to which regulatory agencies are subject, requiring such agencies to make politically-acceptable decisions and to pay "somewhat less attention" to their scientific basis.

"The classification of carcinogens is a scientific, not a regulatory question, and would be much better handled by an independent group of scientific people than by a regulatory agency" according to Dr Ellwood P. Blanchard of the Dupont Company, a member of the AIHC steering committee.

David Dickson

\title{
Dioxin meeting recommends cancer study
}

Since the release of dioxin (the isomer $2,3,7,8$ tetrochloro dibenzo-p-dioxin) over a populated area at Seveso in Italy on 10 July 1976, there has been fear that the chemical is a carcinogen. Few data have been available, but it is beginning to seem that the fear is justified; hence the meeting in Lyons last week hosted by the International Agency for Research in Cancer (IARC) and the US National Institute of Environmental Health Sciences. The conclusion of the meeting was that a major epidemiological survey should be established.

It is now known that there have been at least 14 incidents in different chemical plants throughout the world where workers have been exposed to chlorinated dibenzo dioxin. In two cases the public has been exposed: at Seveso and in the herbicide spraying programme in Vietnam. In the latter cases large populations were exposed to low levels of dioxin; but while these populations must be monitored to assess the public health risk associated with low level exposure, at Lyons the opinion was that little could be learned from them. If dioxin exposure was to be unambiguously related to clinical and pathological findings, the meeting argued, the chemical plant workers were the group to monitor.

Three of the industrial accidents discussed in Lyons occurred between 20 and 30 years ago. Evidence is available from one of these accidents to suggest that in recent years there has been a marked increase in certain types of carcinoma in workers exposed to dioxins.

However the importance of this finding is marred by the small numbers of workers monitored. The meeting considered that it was therefore an urgent matter for a larger population to be studied to detect trends in carcinoma incidence which would be statistically significant. It urged the chemical companies concerned to make their records available for scrutiny. And the meeting stated in no uncertain terms that all the workers exposed to dioxin-whether they are still employed by companies or employed elsewhere--must be located. Mortality trends for this population must be collected.

Two groups reported animal studies to test the carcinogenicity of dioxin : the first directed by $\mathrm{Dr}$ James Allen at the University of Wisconsin, and the second by the Doll Chemical Company. Both research teams identified the dioxin as a carcinogen. But the Wisconsin team claims that the chemical is carcinogenic at a concentration 700 times lower than the level that produce tumours in Doll's study. Reasons for the discrepancy are still not clear, but it was pointed out at the meeting that the Wisconsin study is based on an extremely low number of animals.

Some of the companies involved in dioxin accidents fear further independent investigation, not wishing to run the risk of vast compensation claims. And the meeting felt that, if companies made it a condition that their participation in a dioxin workers' survey were to be treated in confidence, this wish must be respected. The view was that, wherever the blame lies, the most important task at the moment is the compilation of information; and this the IARC is willing to undertake. Dr Rodolfo Saracci of the Unit of Immunology and Bio-Statistics agreed to direct some of this work.

The IARC will act as a clearing house for data on chlorinated dibenzo dioxin-with the help of a permanent secretariat co-opted from participants at the meeting. One of its first tasks will be the production of a list of recommended clinical procedures for examining people exposed to dioxin. It will be stressed that where possible the clinical findings should be related to body dioxin levels - the 'body burden'. This information together with the mortality data should leave the IARC better able to assess the danger to health caused by exposure to dioxins; cancer may be only one of the possible risks.

Alistair Hay

\section{NASA chooses its space lab candidates}

FollowiNG; a similar announcement from the European Space Agency (Nature, January 5), the US National Aeronautics and Space Administration has announced the six American scientists from whom one will be selected as a payload specialist on the first flight of Spacelab, due to be flown in NASA's Space Shuttle in 1980.

The names of the finalists are:

Dr Craig L. Fischer (40), of the Palm Desert Medical Group Inc, California; Dr Michael L. Lampton (36), of the University of California, Berkeley; Byron K. Lichtenberg (29), Massachusetts Institute of Technology; Dr Robert T. Menzies (34). NASA Jet Propulsion Laboratory, Pasadena, California; Ann F. Whittaker (38), NASA, Marshall Space Flight Center, Huntsville; and Dr Richard J. Terrile (26), California Institute of Technology, Pasadena.

Five of the ten candidates that have now been namred by NASA and ESA will undergo extensive training following a final selection in early spring. Ofthese, two will go into space, while the other three will perform support and advisory roles in the control centre on earth.

\section{Government accuses nuclear industry of using propaganda}

THE US Government has accused its industrial partner in its fast breeder reactor development project at Clinch River, Tennessee, of producing pam- 
phlets that give an "oversimplified" and "distorted" view of the dangers of nuclear power.

In a report published in Washington last week, the General Accounting Office said that the Breeder Reaction Corporation of Oak Ridge, Tennessee, which represents almost 700 companies involved in the fast breeder programme, had produced a series of thirteen pamphlets about the programme, at least four of which "clearly constitute propaganda and as such are questionable for dissemination to the public".

In particular, the $\mathrm{GAO}$ questioned the statement in one pahphlet that plutonium is "not a realistic threat when compared with other hazardous materials". It says that the pamphlet grossly understates the dangers, and does not inform readers that plutonium is extremely toxic, and in some circumstances carcinogenic.

\section{US ban use of prisoners in drug research}

THE US Department of Health, Education and Welfare is planning to ban the use of prisoners for drug research not directly related to their health or well-being.

This suggestion follows last year's report of the Commission for the Protection of Human Subjects of Biomedical and Behavioural Research, suggesting stringent conditions on such research to ensure that the participatin of prisoners was voluntary.

In its response to comments on the Commission's report, published last week (January 6), the department says that the Commission found "a paucity of evidence" that research testing of drugs involving minimal risk on prisoners was necessary (see p. 197).
In issuing proposed regulations on research involving prisoners, the department has therefore suggested that the use of prisoners for biomedical and behavioural research studies other than those relating directly to the causes and conditions of their imprisonment, and their well-being in prison, should be banned.

"The Department has concluded that the need to assure that research on human individuals is performed only o human subjects is performed only on indiviuals who have knowingly and voluntarily consented to participate far outweighs any need that has been shown for the use of prisoners in these studies" it says.

David Dickson
THE high rate of rickets in children of Asian origin in Britain is causing concern, and a demand that the government "does something about it". One suggestion is that various foods including the flour used to make chapatis, should be fortified with vitamin $D$. This proposal is being resisted by some scientists, because the present addition of calcium and vitamins to bread, and of vitamins to margarine, is now under attack. It is pointed out that there is little or no evidence that this costly and complicated scheme is having any beneficial effect on the nutritional standards of the population, and that more experimental evidence should be sought. It is probable that if every Asian child in Britain took a spoonful of codliver oil daily, rickets would disappear among this section of our population. Efforts to ensure that the vitamin went where it was needed would be more effective than giving everyone unnecessary and unwanted supplements.

Those who favour more mass fortification of food have the mistaken belief that as we all need small amounts of substances like vitamin D to preserve our health, then the more we consume of them the healthier we will become. This false opinion is perpetuated by many advertisements. I have before me one which tells me this preparation is rich in protein, iron and vitamins $\mathbf{B} 1$ and $\mathbf{B} 2$. It goes on to say that protein is essential for growth and bodily repairs, iron to nourish the blood, and the vitamins to aid digestion, convert food to energy and to maintain tissues such as nerves, muscles and the skin, and generally to promote "vitality". Seed

\section{Enough is enough}

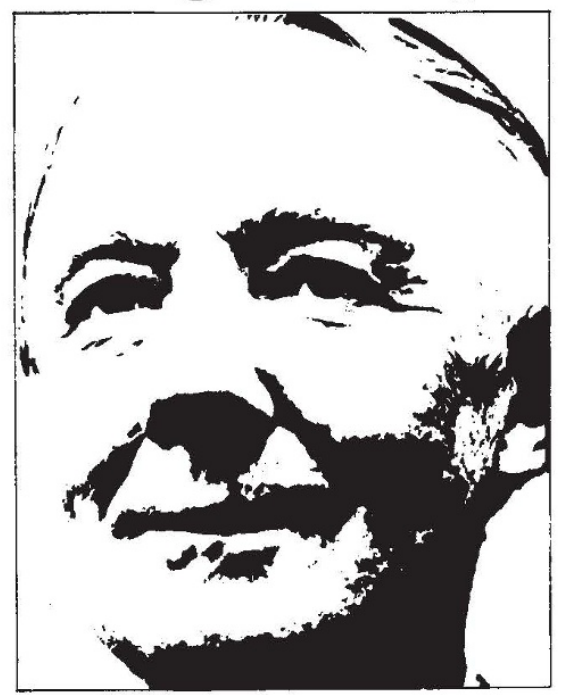

KENNETH MELLANBY

merchants tell us that the more expensive varieties of vegetables give plants particularly full of protein, and with extra amounts of vitamin $\mathrm{C}$ and minerals. Once again they claim that these substances must be taken if we are to remain healthy.

All these statements about the need to eat protein and vitamins are of course true, and if we were living on deficient diets the advertised commodities would no doubt do us good. But when our diet contains the required minimum of these substances, and addition is generally useless and often harmful.

Unfortunately in Britain it is often the better educated who talk the most nonsense about diet. They have learned some of the elements of nutrition and know all about deficiency diseases. They seldom realise that most of our over-fed adults have a surplus of protein and other essentials, and that most of the allegedly health-giving supplements would be best flushed down the drain.

Yet malnutrition, in various forms, is common. In all Western countries the most common and obvious form is gluttony with consequent obesity. Those who try to slim by eating less are subject to a barrage of advertisements for low-calorie foods containing large amounts of supplements. These are generally unnecessary, for the slimmer lives on a nutritious diet of (his own) human flesh. Then the appalling state of our teeth is a symptom of some dietary inbalance, partly but not entirely connected with our overconsumption of sugar. But on the whole most adults seem not to be short of protein and vitamins, so more of these are not "good for them". The only common deficiency would seem to be fibre, and there is evidence to suggest that added bran does some good, but most supplements seem to be useless or harmful.

The position with young children and the elderly is rather different. These groups have a limited food intake, and in Britain today up to half of their calories may come from sugar, in sweetmeats for children, in hot sweet tea for the old. This leaves little room for essential nutrients, so it may be necessary to add these in concentrated form. But it would be more sensible to cut down on the sugar, which, in excess, is always harmful. 